Campos Neutrais - Revista Latino-Americana de Relações Internacionais Vol. 2, $\mathrm{N}^{\mathrm{O}}$ 3, Setembro-Dezembro de 2020. Santa Vitória do Palmar - RS.

\title{
As vulnerabilidades sociais e econômicas no direito internacional: questão boliviana e a necessidade de saída para o mar do Pacífico
}

\author{
Florisbal de Souza Del'Olmo* \\ Tatiana Bruhn Parmeggiani Gomes ${ }^{* *}$
}

Resumo: O presente estudo visa investigar os fatores que levam aos persistentes reclamos da Bolívia contra o Chile pelo acesso às águas do Pacífico, os quais deram origem ao caso Obligation to negotiate access to the Pacific Ocean (Bolivia v. Chile), julgado, recentemente, pela Corte Internacional de Justiça na Haia, Holanda. Para tanto, decidiu-se perpassar pelas disputas históricas envolvendo estes dois países, embates estes que reforçam as fronteiras sul-americanas, exacerbando as vulnerabilidades presentes, sejam elas sociais ou econômicas. Observa-se, ao longo do desenvolvimento do artigo, quanto do enfrentamento da matéria no Tribunal Internacional de Haia e das reflexões promovidas pela Convenção das Nações Unidas sobre o Direito do Mar, uma vez que o seu texto abarca questões de delimitação marítima, a qual tem importante relevância na clarificação de princípios e de normas atreladas à questão. Como considerações finais, enxerga-se a Bolívia, hoje, como o coração da América do Sul, devido à sua localização geográfica única e aos seus valiosos recursos naturais. Os fatores que levam à persistência da reivindicação marítima da Bolívia em relação ao Chile se dão em virtude de enfraquecimentos econômicos que acometem o desenvolvimento do país, o impedindo de negociações mais favoráveis com agentes estrangeiros.

Palavras-chave: Bolívia; Chile; Corte Internacional de Justiça; Disputa marítima; Direito Internacional.

\section{Social and economic vulnerabilities in international law: Bolivian issue and the need to go out to the Pacific Sea}

\begin{abstract}
The present study aims to investigate the factors that lead to Bolivia's persistent claims against Chile for access to Pacific waters, which gave rise to the case recently investigated by the International Court of Justice (Bolivia v. Chile) in The Hague, Netherlands. To this end, it was decided to go through the historical disputes involving these two countries, which clashes that reinforce the South American borders, exacerbating the present vulnerabilities, whether social or economic. It is observed, throughout the development of the article, the confrontation of the matter in The Hague International Court and the reflections promoted by the United Nations Convention on the Law of the Sea, since its text covers maritime delimitation issues, which have important relevance in clarifying the principles and norms linked to the issue. As a final consideration, Bolivia is now seen as the heart of South America because of its unique geographical location and valuable natural resources, and the factors leading to Bolivia's continuing maritime claim to Chile are due to economic weaknesses that affect the country's development, preventing it from more favorable negotiations with foreign agents.
\end{abstract}

Keywords: Bolivia; Chile; International Court of Justice; Maritime dispute; International Law

\section{Introdução}

Dado que a terra - e o mar - e os espaços aéreos do planeta Terra são compartilhados e não são, naturalmente, distribuídos entre os Estados do mundo, proporcionando, assim, que as atividades transformadoras ao redor dele, especialmente, as econômicas, possam ter efeitos diretos ou cumulativos; em grande parte, no meio ambiente

\footnotetext{
* Professor colaborador do Curso de Pós-Graduação em Direito Mestrado e Doutorado do Centro Universitário Curitiba (UNICURITIBA).

** Professora no Instituto Brasileiro de Ensino, Desenvolvimento e Pesquisa (IDP) de Brasília. Doutoranda em Direito Internacional pela Universidade Federal do Rio Grande do Sul (UFRGS).
} 
Campos Neutrais - Revista Latino-Americana de Relações Internacionais Vol. 2, $\mathrm{N}^{\mathrm{O}}$ 3, Setembro-Dezembro de 2020. Santa Vitória do Palmar - RS.

global, o direito internacional tem o desafio de conciliar a interdependência inerente e fundamental desses recursos ${ }^{1}$.

Tem-se, neste cenário, um papel crescente atribuído à água, sob a óptica do direito internacional econômico. Tal fenômeno ocorre em virtude de o direito à água estar associado ao respeito, ao princípio de não discriminação, ou seja, ele promove a acessibilidade física e econômica à água das camadas menos favorecidas da população, aquelas mais vulneráveis, que estão à margem da sociedade. Nesse sentido, Paulo Borba Casella ensina que a equidade também terá o seu papel, uma vez que ela atua na determinação de tarifação que leva em conta a distinção entre grupos sociais mais favorecidos e menos favorecidos ${ }^{2}$.

O interesse crescente, do ponto de vista do direito internacional econômico quanto à dimensão da água, se localiza a partir de questões referentes às transferências internacionais de águas e, em especial, no que atende a este estudo, atento à necessidade boliviana de haver uma saída para as águas do Pacífico ${ }^{3}$. O tema é sensível, haja vista que a Bolívia tem direito a utilizar portos chilenos para exportações e importações, todavia não detém soberania ante a situação, não possuindo direito pleno sobre eles. Investigam-se, neste artigo, quais os fatores que levam aos persistentes reclamos da Bolívia contra o Chile.

Nas palavras de Georges de Leener, aponta-se que o princípio mais antigo consagrado, em matéria de direito das comunicações internacionais, concerne à liberdade dos mares, na medida em que se trata do mar aberto e do oceano. A navegação é livre em alto mar. Nas águas territoriais, esta não pode, tampouco, ser submetida a qualquer entrave. Do ponto de vista de sua utilidade econômica, a liberdade de navegação do alto mar não teria, praticamente, sentido se a liberdade da navegação comercial pudesse ser entravada nas águas territoriais. Nestas, a liberdade de navegação não existe para os navios de guerra, como no alto mar ${ }^{4}$.Dito isso, entende-se que o mundo contemporâneo precisa estar pautado em modelos de ordenação de convivência, multilateralmente instaurados e aplicados,

\footnotetext{
${ }^{1}$ SANDS, Philippe. Principles of International Environmental Law. 2. ed, London: Cambridge University Press, 2003, p. 3. Sobre isso, esclarece Pierre-Marie Dupuy que os espaços de uso internacional atendem às categorias internacional e territorial. Os espaços dessa segunda categorização competem a um Estado determinado, mas os espaços, contrários ao território terrestre propriamente dito, são enfrentados como um caso de zonas marítimas costeiras. DUPUY, Pierre-Marie. Droit International Public. 4. ed. Paris: Dalloz, 1998, p. 594.

${ }^{2}$ CASELLA, Paulo Borba. Direito internacional dos espaços. São Paulo: Atlas, 2009, p. 353.

${ }^{3}$ CASELLA, Paulo Borba. Direito internacional dos espaços. São Paulo: Atlas, 2009, p. 353.

${ }^{4}$ LEENER, Georges de. Règles générales du droit des communications internationales. Recueildes Cours, Académie de Droit International de La Haye, vol. 55, p. 1-86, 1936.
} 
podendo ser o parâmetro para o funcionamento de um sistema internacional adequado para o maior número possível de Estados e, como tal, aceitável para esses mesmos sujeitos de direito internacional ${ }^{5}$.

Parte-se para o enfrentamento da matéria da questão boliviana de reivindicação de livre acesso ao Oceano Pacífico. Para tanto, inicialmente, traça-se um panorama histórico de disputas entre Bolívia e Chile, e, depois, se perpassa perante a análise do caso sob apreciação do Tribunal Internacional da Haia e da influência das reflexões promovidas pela Convenção das Nações Unidas sobre o Direito do Mar, para, ao final, analisar esses impactos sociais e econômicos. Destaca-se que o presente trabalho adota os métodos de pesquisa dedutivo (do geral para o específico) e dialético (contraposição de ideias), dandose destaque à bibliografia nacional e internacional acerca da matéria e aos dados coletados da jurisprudência.

\section{A disputa histórica entre Bolívia e Chile: a consolidação de fronteiras sul- americanas}

Passa-se, agora, à análise da disputa histórica entre Bolívia e Chile, que gerou impasses jurídicos sobre as fronteiras sul-americanas, os quais serão observados com afinco quando do acompanhamento do litígio levado ao Tribunal Internacional da Haia. Primeiramente, cuida-se do desenvolvimento histórico da questão.

A Bolívia está situada na América do Sul, possui fronteira com o Chile a sudoeste, Peru a oeste, Brasil ao norte e leste, Paraguai ao sudeste e Argentina ao sul. A Bolívia é um Estado desprovido de costa marítima. Já o Chile, por sua vez, compartilha uma fronteira terrestre com o Peru ao norte, com a Bolívia ao nordeste e com a Argentina ao leste, e sua costa continental enfrenta o Oceano Pacífico a oeste ${ }^{6}$.

Tanto Bolívia quanto Chile alcançaram sua independência da Espanha em 1818 e 1825, respectivamente. Data-se que, no momento da sua independência, a Bolívia tinha um litoral ao longo do Oceano Pacífico, medindo várias centenas de quilômetros. Todavia, em 10 de agosto 1866, Chile e Bolívia assinaram um Tratado de Limites Territoriais, que estabeleceu uma "linha de demarcação de fronteiras" entre os dois Estados, separando os territórios vizinhos da costa do Pacífico. Esta linha foi confirmada como a fronteira do

\footnotetext{
${ }^{5}$ CASELLA, Paulo Borba. Direito internacional dos espaços. São Paulo: Atlas, 2009, p. 367.

${ }^{6} \mathrm{KU}$, Julian G. Introductory note to obligation to negotiate access to the Pacific Ocean (Bolivia v. Chile). International Legal Materials, vol. 55, n. 1, 2016, p. 74-91. Disponível em: 〈https://www.heinonline.org〉. Acessoem: nov. 2019.
} 
Tratado de Limites entre Bolívia e Chile, assinada em 06 de agosto de $1874^{7}$.

Em 1879, o Chile veio por declarar guerra ao Peru e à Bolívia, a qual ficou conhecida como Guerra do Pacífico. No curso dessa guerra, o Chile ocupou o território da Bolívia e todo seu território costeiro. As hostilidades findaram-se entre Bolívia e Chile com o Pacto de Trégua assinado, em 1884, na cidade de Valparaiso, no Chile. Sob os termos do Pacto de Trégua, o Chile deveria continuar a governar a região costeira. Como resultado desses eventos, a Bolívia perdeu o controle sobre sua costa do Pacífico ${ }^{8}$.

Em 1895, um Tratado de Transferência de Territórios foi assinado entre Bolívia e Chile, mas nunca entrou em vigor. Este Tratado incluiu disposições para a Bolívia recuperar o acesso ao mar, desde que o Chile adquira soberania sobre certos territórios específicos. Em 20 de outubro 1904, as Partes assinaram o Tratado de Paz e Amizade, que, oficialmente, terminou a Guerra do Pacífico entre Bolívia e Chile. Nos termos deste Tratado, que entrou em vigor em 10 de março 1905, todo o território costeiro boliviano tornou-se chileno, e a Bolívia obteve o direito de trânsito comercial aos portos chilenos ${ }^{9}$. O Tratado segue vigente até hoje, mas a Bolívia acusa o Chile de não cumprir algumas de suas cláusulas - algo que o governo chileno nega.

A questão da saída para o mar é motivo de tremenda tensão entre o governo do Chile e da Bolívia. Recentemente, travou-se uma disputa pelos dois países no Tribunal Internacional de Haia, com a Bolívia solicitando da Corte Internacional uma decisão que force o governo chileno a iniciar negociações para solucionar essa questão, considerada de grande importância nacional na Bolívia. Passa-se aos detalhes deste litígio posto à Corte de Haia no tópico a seguir.

\section{O enfrentamento no Tribunal Internacional de Haia: a negociação de acesso às águas do Pacífico}

Na percepção de Edmundo Vargas Carreño, ex-presidente da Comissão de Direito Internacional das Nações Unidas, a Corte Internacional de Justiça, também conhecida como Tribunal Internacional de Haia, é o órgão judicial mais importante da atualidade,

\footnotetext{
${ }^{7} \mathrm{KU}$, Julian G. Introductory note to obligation to negotiate access to the Pacific Ocean (Bolivia v. Chile). International Legal Materials, vol. 55, n. 1, 2016, p. 74-91. Disponível em: 〈https://www.heinonline.org〉. Acesso em: nov. 2019.

${ }^{8} \mathrm{KU}$, Julian G. Introductory note to obligation to negotiate access to the Pacific Ocean (Bolivia v. Chile). International Legal Materials, vol. 55, n. 1, 2016, p. 74-91. Disponível em: 〈https://www.heinonline.org〉. Acessoem: nov. 2019.

${ }^{9} \mathrm{KU}$, Julian G. Introductory note to obligation to negotiate access to the Pacific Ocean (Bolivia v. Chile). International Legal Materials, vol. 55, n. 1, 2016, p. 74-91. Disponível em: 〈https://www.heinonline.org〉. Acesso em: nov. 2019.
} 
Campos Neutrais - Revista Latino-Americana de Relações Internacionais Vol. 2, $\mathrm{N}^{\mathrm{O}}$ 3, Setembro-Dezembro de 2020. Santa Vitória do Palmar - RS.

pois não é um tribunal arbitral constituído por um advogado especial das partes para resolver certa controvérsia, e sim uma instituição preestabelecida em um instrumento internacional que possui jurisdição e regulamentação de funcionamento ${ }^{10}$.

Nesse sentido, em meados de 2013, a Bolívia apresentou uma demanda ao Tribunal Internacional de Haia para obrigar o Chile a negociar um acesso soberano ao Oceano Pacífico. Após a derrota na Guerra do Pacífico, o país cedeu ao Chile 400 quilômetros de costa e 120 mil quilômetros quadrados de território, num Tratado de fronteira assinado em 1904 (como visto anteriormente).

Porém, a presente controvérsia estava apenas por começar, haja vista que a ação movida pelo presidente Evo Morales à época procurava alcançar três declarações da Corte Internacional de Justiça: que o Chile tinha a obrigação de negociar com a Bolívia para chegar a um acordo para conceder um acesso soberano ao mar; que o Chile não tinha cumprido essa obrigação; e que tinha que cumpri-lo de boa-fé, formal e prontamente, dentro de um prazo razoável e de maneira efetiva ${ }^{11}$.

Sebastián López Escarcena recorda que a obrigação de negociar com boa-fé pode ser contraída de diversas maneiras e advém do direito internacional geral ${ }^{12}$. Nas cláusulas de resolução de disputas internacionais de certos Tratados, as negociações entre as partes são antecedentes ou pré-requisito para o uso dos meios judiciais acordados. Frisa-se que a Corte Internacional assinalou que a obrigação de negociar não requer, necessariamente, o alcance de acordo $^{13}$.

Ao longo desses anos de discussão, Evo Morales adotou não apenas uma estratégia legal, mas também comunicativa, diplomática e política. A Bolívia defendia que o Chile havia se comprometido ao longo dos anos a negociar o acesso soberano ao mar, por meio de acordos, de práticas diplomáticas e de declarações de representantes do mais alto nível.

O país mantinha, então, uma expectativa positiva quanto ao resultado, baseada em uma vitória da equipe jurídica boliviana em um processo já terminado quando o Chile questionou a competência da Corte Internacional para lidar com a questão. Além disso, a

\footnotetext{
${ }^{10}$ VARGAS CARREÑO, Edmundo. La Corte Internacional de Justicia: su organización y competência. Revista Tribuna Internacional, vol. 3, n. especial, 2014, p. 12.

${ }^{11} \mathrm{KU}$, Julian G. Introductory note to obligation to negotiate access to the Pacific Ocean (Bolivia v. Chile). International Legal Materials, vol. 55, n. 1, 2016, p. 74-91. Disponível em: 〈https://www.heinonline.org〉. Acesso em: nov. 2019.

${ }^{12}$ LÓPEZ ESCARCENA, Sebastián. El asunto de laobligación de negociar um acceso al Océano Pacífico. Comentario de ladecisión sobre excepción preliminar de la Corte Internacional de Justicia, de fecha de 24 de septiembre de 2015. Revista Chilena de Derecho, vol. 43, n. 2, 2016, p. 723.

${ }^{13}$ LÓPEZ ESCARCENA, Sebastián. El asunto de la obligación de negociar um acceso al Océano Pacífico. Comentario de la decisión sobre excepción preliminar de la Corte Internacional de Justicia, de fecha de 24 de septiembre de 2015. Revista Chilena de Derecho, vol. 43, n. 2, 2016, p. 723.
} 
Campos Neutrais - Revista Latino-Americana de Relações Internacionais Vol. 2, $\mathrm{N}^{\mathrm{O}}$ 3, Setembro-Dezembro de 2020. Santa Vitória do Palmar - RS.

reivindicação não se baseava no Tratado Territorial que anula o litoral boliviano desde 1904, o qual é irreversível, mas sim nas chamadas "expectativas de direito", as quais a Bolívia teria adquirido a partir de várias ofertas feitas pelo Chile ao longo do tempo para resolver a disputa bilateral, que não se concretizaram ${ }^{14}$.

Em resposta à solicitação da Bolívia, o Chile levantou uma objeção preliminar à jurisdição da Corte Internacional de Justiça em 15 de julho de 2014. Na ocasião, o Chile argumentou que o Artigo VI, do Pacto de Bogotá, exclui da jurisdição do Tribunal as questões já resolvidas pelo acordo entre as partes, bem como os assuntos regidos por acordos internacionais. Solicitou, também, que a Corte julgue a questão do acesso soberano da Bolívia ao Pacífico - uma questão resolvida no Tratado de Paz de 1904, pedindo, assim, que se negasse provimento à falta de jurisdição na Bolívia ${ }^{15}$.

A Bolívia rebateu a objeção jurisdicional do Chile, alegando que o Chile interpretou mal o objeto da disputa perante o Tribunal Internacional. Toda a disputa diz respeito à obrigação do Chile de negociar o acesso soberano ao Pacífico; o argumento adotado foi que a obrigação surgiu após o Tratado de 1904 e não poderia ter sido estabelecida por esse Tratado ${ }^{16}$.

O Chile, entretanto, defendia que as conversas sempre estiveram fechadas e quase sempre foram frustradas pelo próprio governo boliviano. O país entende que não há disputas de fronteira pendentes entre os dois países e que cumpriu e aprofundou todos os compromissos firmados no Tratado de 1904 e seus acordos complementares, sem perder sua vontade permanente de diálogo ${ }^{17}$.

Todavia, a controvérsia se estendeu, a Corte Internacional de Justiça proferiu sua sentença de mérito em 01 de outubro de 2018, na qual concluiu que o Chile não assumia a obrigação legal de negociar um acesso soberano ao Oceano Pacífico para a Bolívia ${ }^{18}$.

\footnotetext{
${ }^{14}$ De acordo com as informações de: BRASIL. Corte internacional nega pleito da Bolívia para obrigar Chile a negociar acesso ao mar. $O$ Globo, publicação de 01 de outubro de 2018. Disponível em:

<https://oglobo.globo.com/mundo/corte-internacional-nega-pleito-da-bolivia-para-obrigar-chile-negociaracesso-ao-mar-1-23115534>. Acesso em: nov. 2019.

${ }^{15} \mathrm{KU}$, Julian G. Introductory note to obligation to negotiate access to the Pacific Ocean (Bolivia v. Chile). International Legal Materials, vol. 55, n. 1, 2016, p. 74-91. Disponível em: 〈https://www.heinonline.org>. Acessoem: nov. 2019.

${ }^{16} \mathrm{KU}$, Julian G. Introductory note to obligation to negotiate access to the Pacific Ocean (Bolivia v. Chile). International Legal Materials, vol. 55, n. 1, 2016, p. 74-91. Disponível em: 〈https://www.heinonline.org>. Acesso em: nov. 2019.

17 Vide informações de: BRASIL. Corte internacional nega pleito da Bolívia para obrigar Chile a negociar acesso ao mar. $O$ Globo, publicação de 01 de outubro de 2018. Disponível em:

$<$ https://oglobo.globo.com/mundo/corte-internacional-nega-pleito-da-bolivia-para-obrigar-chile-negociaracesso-ao-mar-1-23115534>. Acesso em: nov. 2019.

${ }^{18}$ Dados extraídos da decisão. THE HAGUE. International Courtof Justice. Case Obligation to Negotiate Access to the Pacific Ocean (Bolivia v. Chile). Disponível em: 〈https://www.icj-cij.org/en/case/153>.
} 
Ao fazê-lo, a Corte assinalou que os instrumentos bilaterais invocados pela Bolívia não estabelecem uma obrigação do Chile de negociar o acesso soberano da Bolívia ao Oceano Pacífico; que a obrigação de negociar o acesso soberano da Bolívia ao mar não se baseia em nenhum dos atos unilaterais do Chile referidos pela Bolívia; que a suposta aquiescência do Chile não pode ser considerada uma base legal de uma obrigação de negociar o acesso soberano da Bolívia ao mar; que o impedimento não pode fornecer uma base legal para a obrigação do Chile de negociar o acesso soberano da Bolívia ao mar; que não existe, no direito internacional geral, um princípio que daria origem a uma obrigação com base no que poderia ser considerada uma expectativa legítima, consequentemente, o argumento da Bolívia apoiando-se em expectativas legítimas não pode ser sustentado ${ }^{19}$.

A recente decisão trouxe, também, o entendimento de que as disposições da Carta das Nações Unidas e da Carta da Organização dos Estados Americanos (OEA) invocadas pela Bolívia não poderiam constituir a base legal de uma obrigação de negociar o acesso soberano da Bolívia ao mar; que a Corte não pode deduzir do conteúdo das resoluções da OEA nem da posição do Chile em relação à sua adoção e que o presente Estado aceitou a obrigação de negociar o acesso soberano da Bolívia ao Oceano Pacífico; que, considerando que sua análise mostra que nenhuma obrigação de negociar o acesso soberano da Bolívia ao Oceano Pacífico surgiu para o Chile a partir de qualquer uma das bases jurídicas invocadas individualmente, uma consideração cumulativa das várias bases não pode ser adicionada ao resultado geral ${ }^{20}$.

Corrobora-se, perante o caso em tela, a partir dos ensinamentos de Vicente Marotta Rangel, que as controvérsias surgem e se ampliam à medida que avultam os usos do mar, seja pela quantidade de navios, seja pelo impacto dos processos tecnológicos, à medida que cresce o número dos componentes da comunidade internacional ${ }^{21}$, forçando barreiras que desafiam o direito internacional econômico e o Direito do Mar, ensejando um rico debate atrelado às questões marítimas, que acabam por expor vulnerabilidades históricas e de forte apelo nacional, consolidando, assim, precedentes de estudos que nos permitem equacionar alternativas futuras. Parte-se, na tentativa de traçar esses objetivos, ao último ponto de

\footnotetext{
Acesso em: nov. 2019.

${ }^{19}$ Dados extraídos da decisão. THE HAGUE. International Court of Justice. Case Obligation to Negotiate Access to the Pacific Ocean (Bolivia v. Chile). Disponível em: 〈https://www.icj-cij.org/en/case/153〉. Acesso em: nov. 2019.

${ }^{20}$ THE HAGUE. International Court of Justice. Case Obligation to Negotiate Access to the Pacific Ocean (Bolivia v. Chile). Disponível em: 〈https://www.icj-cij.org/en/case/153>. Acesso em: nov. 2019.

${ }^{21}$ RANGEL, Vicente Marotta. Nova ordem internacional: fundos oceânicos e solução de controvérsias no direito do mar. In: O direito na década de 1990: novos aspectos - estudos em homenagem ao Prof. Arnoldo Wald. São Paulo: Editora Revista dos Tribunais, 1992, p. 366.
} 
Campos Neutrais - Revista Latino-Americana de Relações Internacionais Vol. 2, $\mathrm{N}^{\mathrm{O}}$ 3, Setembro-Dezembro de 2020. Santa Vitória do Palmar - RS.

estudo, o qual lança um olhar especial para a Convenção das Nações Unidas sobre Direito do Mar nas situações jurídicas contemporâneas.

\section{A influência (in)direta da Convenção das Nações Unidas sobre Direito do Mar}

Como visto no ponto anterior, a Corte Internacional de Justiça afastou a Carta ou a Convenção das Nações Unidas sobre o Direito do Mar como substrato jurídico de acesso ao mar do Pacífico. Por outro lado, relevante abordar a influência da existência dessa Convenção que opera no desenvolvimento do Direito Marítimo, uma vez que o seu texto abarca questões de delimitação marítima, a qual tem importante relevância na clarificação de princípios e de normas atreladas à questão. Porém, tal protagonismo foi deixado à parte no tocante aos impactos no litígio por ora estudado, Bolívia v. Chile, mas se devem valorar os efeitos lançados em demais relações jurídicas internacionais.

Na percepção de Bernardo Sepúlveda Amor, a presente Convenção fornece um regime legal abrangente para a disposição do maior recurso do mundo, incluindo a regulamentação de uso, a atribuição de zonas marítimas e o fornecimento de procedimentos obrigatórios de soluções de controvérsias ${ }^{22}$. É especialmente a lei moderna do mar, composta, em grande parte, através de uma série de decisões legais - emanadas, não apenas, pela Corte Internacional de Justiça, mas também por vários outros tribunais arbitrais $^{23}$. Tal posicionamento, diante da matéria, coaduna para a evolução subsequente do regime jurídico marítimo e cumpre com o objetivo comum de um corpus de direito internacional que se reforça, mutuamente, na resolução de disputas marítimas internacionais.

Historicamente, Júlio Soares de Moura Neto destaca a Organização das Nações Unidas (ONU) - idealizada para zelar pela paz e pela segurança internacional - fomentou a consolidação da regulação marítima ${ }^{24}$. Várias tentativas frustraram essa expectativa. Apesar dos progressos decorrentes da primeira e da segunda Conferência da ONU, pouco se avançou na obtenção do consenso em algumas questões mais delicadas. Nesse ínterim que se desenvolve a importância da terceira Conferência, que culminou com a Convenção das Nações Unidas sobre o Direito do Mar, assinada por expressiva representação de

${ }^{22}$ SEPÚLVEDA AMOR, Bernardo. The International Court of Justice and the Law of the Sea. Anuario Mexicano de Derecho Internacional, p. 3-26, 2012. Disponível em: <https/:http://www.corteidh.or.cr/tablas/r29686.pdf〉. Acesso em: nov. 2019.

${ }^{23}$ SEPÚLVEDA AMOR, Bernardo. The International Court of Justice and the Law of the Sea. Anuario Mexicano de Derecho Internacional, p. 3-26, 2012. Disponível em: <https/:http://www.corteidh.or.cr/tablas/r29686.pdf>. Acesso em: nov. 2019.

${ }^{24}$ MOURA NETO, Júlio Soares de. Prefácio. In: BEIRÃO, André Panno; PEREIRA, Antônio Celso Lopes (Orgs.). Reflexões sobre a Convenção do Direito do Mar. Brasília: FUNAG, p. 16, 2014. 
Estados, em 10 de dezembro de 1982, em Montego Bay, Jamaica ${ }^{25}$.

Nessa senda, Vicente Marotta Rangel ressalta que a grande novidade de cunho institucional, gerada pela Convenção, é o Tribunal Internacional sobre o Direito do $\mathrm{Mar}^{26}$, sediado em Hamburgo, Alemanha, além da consagração de todo um rol dedicado à temática de solução de controvérsias; tem-se, portanto, a admissão de procedimentos clássicos ao lado de outros inovadores ${ }^{27}$. Sobre isso, versa Louis Yves Fortier, embaixador do Canadá nas Nações Unidas, de 1988 a1992, sobre a necessidade de preservação dos instrumentos, salientando o papel da Corte de Haia e do Tribunal do Mar, por permitir a solução dos conflitos como um braço das Nações Unidas para manter a paz internacional ${ }^{28}$.

Concernente ao litígio travado entre Bolívia v. Chile, tem-se que causa marítima boliviana inclui não só questões de soberania, mas também exemplos concretos de prejuízos econômicos para o país. Latente à controvérsia que se perpetua ao longo dos anos, por mais que se tenha restado uma negativa aos apelos da Bolívia por parte da Corte Internacional de Justiça, há indícios de futuras solicitações ao Chile. Todavia, o que se busca esclarecer, nesse ponto, é que, cada vez mais, se avança em mecanismos no arcabouço jurídico do direito marítimo.

Jacques Ancel, em seu curso proferido na Academia de Direito Internacional de Haia, em 1936, já falava da relatividade geográfica das fronteiras, utilizando-se do exemplo da América do Sul, afirmando que os rios fronteiriços, muitas vezes, brincam com as relações diplomáticas dos países ${ }^{29}$. O autor, inclusive, cita o exemplo das nações andinas; para ele, os rios chilenos, por possuírem um nível baixo e próximo da base, são "trabalhadores" e "conquistadores": mordem constantemente, apoiando suas fontes, nos rios argentinos ${ }^{30}$.

${ }^{25}$ MOURA NETO, Júlio Soares de. Prefácio. In: BEIRÃO, André Panno; PEREIRA, Antônio Celso Lopes (Orgs.). Reflexões sobre a Convenção do Direito do Mar. Brasília: FUNAG, p. 16, 2014.

${ }^{26}$ Frisa-se que instituições tradicionais como a Corte Internacional de Justiça remanescem, no sistema da Convenção, conjuntamente com o Tribunal Internacional sobre o Direito do Mar e sua Câmara de Controvérsia sobre os Fundos Marinhos. Ver: RANGEL, Vicente Marotta. Nova ordem internacional: fundos oceânicos e solução de controvérsias no direito do mar. In: O direito na década de 1990: novos aspectos estudos em homenagem ao Prof. Arnoldo Wald. São Paulo: Editora Revista dos Tribunais, 1992, p. 383.

${ }^{27}$ RANGEL, Vicente Marotta. Nova ordem internacional: fundos oceânicos e solução de controvérsias no direito do mar. In: O direito na década de 1990: novos aspectos - estudos em homenagem ao Prof. Arnoldo Wald. São Paulo: Editora Revista dos Tribunais, 1992, p. 375 e ss.

${ }^{28}$ FORTIER, L. Yves. The Contribution of the United Nations to the Development of International Law. Lunchtime Seminars at the Peace Palace, 19 october 2012, p. 2-8. Disponível em: <https://www.peacepalacelibrary.nl/>. Acesso em: nov. 2019.

${ }^{29}$ ANCEL, Jacques. Les frontières - étude de géographie politique. Recueildes Cours. La Haye: Académie de Droit International de La Haye, vol. 55, 1936, p. 211.

${ }^{30}$ No original, em língua francesa, "travailleuses et conquérantes". Ver: ANCEL, Jacques. Les frontières étude de géographie politique. Recueildes Cours. La Haye: Académie de Droit International de La Haye, vol. 55, 1936, p. 211. Tradução livre dos autores. 
A situação que acomete à Bolívia é ainda mais crítica, pois ela se encontra "enclausurada", fortemente dependente do transporte terrestre, fato que encarece suas mercadorias, perdendo em competividade com os produtos chilenos e peruanos ${ }^{31}$. Nos estudos desenvolvidos por Eva Verschoor, em 2017, evidenciou-se que os setores mais importantes da economia boliviana foram privatizados e o investimento estrangeiro aumentou. Com esse modelo, criou-se certa dependência econômica, e a administração de Evo Morales se colocou contrária a esta forma de dependência, almejando, assim, maior liberdade.

Percebe-se a Bolívia, hoje, como o coração da América do Sul, devido à sua localização geográfica única e aos seus valiosos recursos naturais ${ }^{32}$.Pode-se alegar que, através do acesso ao mar, essa independência tão desejada poderá vir a ser alcançada. Essa proteção vai além da importância do território, enfatiza a relevância da proteção do Estado. O acesso soberano ao Oceano Pacífico vislumbra a probabilidade de ampliar o comércio com os países estrangeiros. Portanto, analisar a influência da Convenção das Nações Unidas sobre o Direito do Mar e as soluções que ela traz transpassa a magnitude do interesse individual dos países e coloca, em evidência, o trânsito aquaviário internacional.

\section{Considerações finais}

Diante do que foi exposto ao longo do trabalho, há vultos de possíveis novos entraves envolvendo Bolívia e Chile. Compreende-se que está se falando de disputas que remontam ao final do século XIX e ao início do século XX, ou seja, estão distantes de se darem findas por completo.

Todavia, se faz importante pontuar que o sentimento histórico, juntamente com as desvantagens econômicas, que desvelam as vulnerabilidades da Bolívia e sua inserção na América Latina, se transformou em um sentimento nacional dentro do país. Nesse contexto, o litígio Obligation to negotiate access to the Pacific Ocean (Bolivia v. Chile) levado ao Tribunal Internacional de Haia revela vicissitudes muito mais complexas que esbarram em princípios de soberania, em relações diplomáticas e de enfrentamentos futuros em matéria de Direito do Mar e de Direito Internacional Econômico.

\footnotetext{
${ }^{31}$ VERSCHOOR, Eva. Geopolitics, nationalism or personal interest: Morales' aspiration to have Bolivian beaches: the persistence of the maritime claim towards Chile in the political agenda of Evo Morales. Leiden University, Master thesis of Latin American Studies, Supervisor Dr. S. Valdivia, 62 p., 2017. Disponível em: <https://www.peacepalacelibrary.nl/>. Acesso em: nov. 2019.

32 VERSCHOOR, Eva. Geopolitics, nationalism or personal interest: Morales' aspiration to have Bolivian beaches: the persistence of the maritime claim towards Chile in the political agenda of Evo Morales. Leiden University, Master thesis of Latin American Studies, Supervisor Dr. S. Valdivia, 62 p., 2017. Disponível em: <https://www.peacepalacelibrary.nl/>. Acesso em: nov. 2019.
} 
Campos Neutrais - Revista Latino-Americana de Relações Internacionais Vol. 2, $\mathrm{N}^{\mathrm{O}}$ 3, Setembro-Dezembro de 2020. Santa Vitória do Palmar - RS.

Espera-se que se encontrem alternativas para os pleitos por ora levantados pela Bolívia e que, cada vez mais, se ampliem as esferas jurídicas de proteção e de consolidação de direitos. Segue-se na linha de valorização dos mecanismos internacionais de solução de controvérsias e do expressivo trabalho da Organização das Nações Unidas em temas marítimos.

Por fim, conclui-se que os fatores que levam à persistência da reivindicação marítima da Bolívia em relação ao Chile se dão em virtude de enfraquecimentos econômicos que acometem o desenvolvimento do país, impedindo-o de negociações mais favoráveis com agentes estrangeiros.

\section{Referências}

ANCEL, Jacques. Les fronteires-étude de géographie politique. Recueildes Cours. La Haye: Académie de Droit International de La Haye, vol. 55, p. 201-297, 1936.

BEIRÃO, André Panno; PEREIRA, Antônio Celso Lopes (Orgs.). Reflexões sobre a Convenção do Direito do Mar. Brasília: FUNAG, 2014.

BRASIL. Corte internacional nega pleito da Bolívia para obrigar Chile a negociar acesso ao mar. $O$ Globo, publicação de 01 de outubro de 2018. Disponível em: <https://oglobo.globo.com/mundo/corte-internacional-nega-pleito-da-bolivia-para-obrigar-chilenegociar-acesso-ao-mar-1-23115534>. Acesso em: nov. 2019.

CASELLA, Paulo Borba. Direito internacional dos espaços. São Paulo: Atlas, 2009.

DUPUY, Pierre-Marie. Droit International Public.4. ed. Paris: Dalloz, 1998.

FILLIPI, Eduardo Ernesto; CHARÃO, Carla Carpim. Chile e Bolívia e o conflito para alcançar o oceano: Guerra do Pacífico e mudanças nas relações entre os dois países. Revista Conjuntura Austral, v. 6, n. 27-28, p. 54-75, dez. 2014 - mar. 2015.

FORTIER, L. Yves.The Contribution of the United Nations to the Development of International Law. Lunchtime Seminars at the Peace Palace, 19 october 2012, p. 2-8. Disponível em:<https://www.peacepalacelibrary.nl/>. Acesso em: nov. 2019.

$\mathrm{KU}$, Julian G. Introductory note to obligation to negotiate access to the Pacific Ocean (Bolivia v.Chile). International Legal Materials, vol. 55, n. 1, 2016, p. 74-91. Disponível em: <https://www.heinonline.org >. Acesso em: nov. 2019.

KU, Julian G; YOO, John.Globalization and Sovereignty.Berkeley Journal of International Law, n. 31, p. 210-235, 2013.Disponível em: 〈<https://www.heinonline.org>. Acesso em: nov. 2019.

LEENER, Georges de. Règles générales du droit des communications internationales. Recueildes Cours. La Haye: Académie de Droit International de La Haye, vol. 55, p. 1-86, 1936.

LÓPEZ ESCARCENA, Sebastián. El assunto de la obligación de negociar um acceso al océano pacífico. Comentario de la decisión sobre excepción preliminar de la Corte Internacional de Justicia, de fecha de 24 de septiembre de 2015. Revista Chilena de Derecho, vol. 43, n. 2, p. 715-734, 2016.

MCCAFREY, Stephen C. The law of international watercourses.3. ed. London: Oxford, 2019.

MOURA NETO, Júlio Soares de. Prefácio. In: BEIRÃO, André Panno; PEREIRA, Antônio Celso Lopes (Orgs.). Reflexões sobre a Convenção do Direito do Mar. Brasília: FUNAG, 2014.

RANGEL, Vicente Marotta. Direito e relações internacionais. 8. ed. São Paulo: Editora Revista 
Campos Neutrais - Revista Latino-Americana de Relações Internacionais Vol. 2, $\mathrm{N}^{\mathrm{O}}$ 3, Setembro-Dezembro de 2020. Santa Vitória do Palmar - RS.

dos Tribunais, 2005.

RANGEL, Vicente Marotta. Nova ordem internacional: fundos oceânicos e solução de controvérsias no direito do mar. In: O direito na década de 1990: novos aspectos - estudos em homenagem ao Prof. Arnoldo Wald. São Paulo: Editora Revista dos Tribunais, p. 365-383, 1992.

SANTA MARIA, Ignácio. La Guerra del Pacífico. Santiago de Chile: Imprenta Universitaria, 1919.

SEPÚLVEDA AMOR, Bernardo. The International Court of Justice and the Law of the Sea.Anuario Mexicano de Derecho Internacional, p. 3-26, 2012. Disponível em:

<https/:http://www.corteidh.or.cr/tablas/r29686.pdf>. Acesso em: nov. 2019.

THE HAGUE. International Court of Justice.Case Obligation to Negotiate Access to the Pacific Ocean (Bolivia v. Chile). Disponível em: 〈https://www.icj-cij.org/en/case/153〉. Acesso em: nov. 2019.

VARGAS CARREÑO, Edmundo. La Corte Internacional de Justicia: su organizacióny competência. Revista Tribuna Internacional, vol. 3, n. especial, p. 11-32, 2014.

VERSCHOOR, Eva. Geopolitics, nationalism or personal interest: Morales' aspiration to have Bolivian beaches: the persistence of the maritime claim towards Chile in the political agenda of Evo Morales. Leiden University, Master thesis of Latin American Studies, Supervisor Dr. S. Valdivia, 62 p., 2017. Disponível em: 〈https://www.peacepalacelibrary.nl/>. Acesso em: nov. 2019. 